\title{
Comparison of Intravenous Co-amoxiclav and Benzyl Penicillin in Children with Severe Streptococcal Tonsillitis
}

\author{
Sumera Akram ${ }^{1}$, Muhammad Ahmed Khan ${ }^{2}$, Abdul Rehman $^{3}$, Hassan Bin Usman ${ }^{4}$, Ali Abbas ${ }^{5}$ \\ ${ }^{1}$ Assistant Professor, Department of Pediatrics, Mardan Medical Complex, KPK Pakistan \\ ${ }^{2}$ ENT Specialist, Combined Military Hospital, Mardan, KPK Pakistan \\ ${ }^{3}$ Associate Professor, Department of Pediatrics, Bahawal Victoria Hospital, Bahawalpur, Pakistan \\ ${ }^{4}$ Public Health Specialist, Ministry of Health, Doha Qatar \\ ${ }^{5}$ Child Specialist, Combined Military Hospital, Mardan, KPK Pakistan
}

\begin{abstract}
A BST RACT
Background: Streptococcal tonsillitis is a common pediatric ailment which is faced by physicians on a daily basis and is associated with disastrous complications if not treated adequately. The objective of this study was to compare the efficacy, safety and cost-effectiveness of intravenous co-amoxiclav with benzyl penicillin in the treatment of severe streptococcal tonsillitis in children.

Material and Methods: This Randomized Controlled Trial was carried out at CMH Mardan, Khyber Pakhtunkhwa from January 2018 to November 2019. A total of 310 children with severe tonsillitis, aged between 5 to 15 years were selected from outpatient department of Combined Military Hospital Mardan. The cases were divided into two groups. Injection co-amoxiclav was given to patients in Group $A(n=155)$ and injection benzyl penicillin was administered to patients in Group B $(n=155)$. Both groups were compared in terms of effectiveness of treatment, safety and cost. All the data was assessed with help of SPSS (Statistical Package for Social Sciences) version 21 . Chi square and independent t-test were used with $P$-value $<0.05$ taken as statistically significant.

Results: There were 310 children with severe tonsillitis, 155 in each group. Mean age in Group A was $9.35 \pm 3.17$ years and in Group B, 9.96 \pm 2.96 years, respectively. In Group A, 2 cases developed hypersensitivity to injection co-amoxiclav after initial test dose as compared to 3 cases in Group B. Mean duration for complete resolution of symptoms (i.e. hospital stay) was $4.13 \pm 0.375$ days for Group A as compared to $4.09 \pm 0.377$ days for Group $B(P=0.458)$. Mean cost of antibiotic drugs for each child in Group A was Rs. $965.88 \pm 298$ and in Group B was Rs. 152.36 \pm 53 . Benzyl penicillin was found to be more cost effective as compared to co-amoxiclav $(P=0.000)$.

Conclusions: Both the drugs have similar efficacy and safety profile in the treatment of severe streptococcal tonsillitis in children. However, benzyl penicillin is more cost effective than co-amoxiclav in our study population.

Key words: Co-amoxiclav, Benzyl penicillin, Efficacy, Safety profile, Streptococcal tonsillitis

Clinical Trail Registration: Clinicaltrials.gov: NCT04215770

\begin{tabular}{lll}
\hline Authors' Contribution: & Correspondence: & Article info: \\
${ }^{1-3}$ Conception; Literature research; & Muhammad Ahmed Khan & Received: January 13, 2020 \\
manuscript design and drafting; ${ }^{4,5}$ Critical & Email: akawan79@gmail.com & Accepted: June 22, 2020
\end{tabular}

analysis and manuscript review; Data analysis; Manuscript Editing.

Cite this article. Akram S, Khan MA, Rehman A, Usman HB, Abbas A. Comparison of Intravenous Co-amoxiclav and Benzyl Penicillin in Children with Severe Streptococcal Funding Source: Nil Tonsillitis. J Islamabad Med Dental Coll.2020; 9(2): 82-87. Doi: 10.35787/jimdc.v9i2.489 Conflict of Interest: Nil
\end{abstract}




\section{Introduction}

Tonsillitis is defined as inflammation of pharyngeal tonsils, although infection may spread to lingual tonsils, adenoids and adjacent tissues. ${ }^{1,2}$ It is mostly caused by viral or bacterial infections. Group A Streptococcal tonsillitis is also called 'Strept Throat'. ${ }^{3}$ Symptoms of tonsillitis include fever, pain throat, dysphagia, odynophagia, headache, chills, malaise, white pus-filled spots or membrane over tonsils and neck node enlargement. ${ }^{4}$ Pain of tonsillitis can also radiate to ears. The patient may also complain of fatigue, halitosis, anorexia, voice change etc. ${ }^{3}$ Most common cause of tonsillitis is viral, caused by adenovirus, rhinovirus, influenza, respiratory syncytial and coronavirus etc. ${ }^{5}$ Second common cause is bacterial tonsillitis. Among bacterial microorganisms, Group A $\beta$-hemolytic streptococcus (GAS), Streptococcus pyogenes is most frequently involved. ${ }^{6,7}$ Staphylococcus aureus (including Methicillin-Resistant Staphylococcus aureus), Streptococcus pneumoniae, Mycoplasma pneumoniae, Chlamydia Pneumoniae, etc. can also be responsible infrequently. ${ }^{8}$ Clinically, streptococcal pharyngitis/tonsillitis is diagnosed with the help of characteristic clinical features along with throat swab culture, which is the gold standard diagnostic test.

In literature, streptococcal tonsillitis, pharyngitis and pharyngotonsillitis have been used synonymously/interchangeably. ${ }^{9,10}$ Prevalence of acute streptococcal pharyngitis /pharyngotonsillitis caused by GAS (Streptococcus pyogenes) varies from 20 to $30 \%$ and is the commonest cause of bacterial tonsillitis requiring antibiotics. ${ }^{11,12}$ The prevalence of acute streptococcal pharyngitis in Pakistan has been reported as $25.3 \% .{ }^{13}$

Streptococcal tonsillitis (tonsillitis or pharyngotonsillitis caused by GAS) requires treatment with antibiotics as it is associated with not only local suppurative complications like peritonsillar abscess, otitis media, mastoiditis and pneumonia but can also cause non-suppurative complications like acute rheumatic fever, acute post-streptococcal glomerulonephritis, poststreptococcal reactive arthritis and pediatric autoimmune neuropsychiatric disorders. Penicillins, macrolides, cephalosporins, and clindamycin are highly sensitive against the Streptococci. ${ }^{11,12}$ Streptococcal tonsillitis can be confirmed in less than 10 minutes with $95 \%$ specificity and $80-90 \%$ sensitivity. ${ }^{13}$ In our resource-constrained country, economic factors are very important with regards to the treatment of streptococcal tonsillitis.

In the present study, we have compared coamoxiclav with benzyl penicillin for the treatment of children with acute streptococcal tonsillitis/pharyngotonsillitis in terms of efficacy, safety and cost-effectiveness.

\section{Material and Methods}

This randomized single-blinded clinical trial was carried out at Combined Military Hospital Mardan, Khyber Pakhtunkhwa Pakistan from January 2018 to November 2019. Permission was sought from the Ethical Review Board of the hospital and informed consent was obtained from the parents/guardian at the start of the study. Sample size was calculated with help of Epitools online sample size calculator. Prevalence of streptococcal pharyngitis was taken as $25.3 \%,{ }^{13}$ with a confidence interval of $95 \%$, sample of 291 was calculated.

Children aged between 5 to 15 years, with a Centor Score for Strep tonsillitis / pharyngotonsillitis of 3 or 4 and those who had a positive Rapid Antigen detection Test (RADT) for Group A beta-hemolytic streptococci were included in the study. Immunocompromised children, those with known allergy to penicillins (co-amoxiclav and benzyl penicillin), those on oral or parenteral antibiotics 
and with liver failure or renal impairment were excluded from the study.

The cases were selected from outpatient department of Combined Military Hospital Mardan, KPK. A child was diagnosed as a case of Streptococcal Tonsillitis/pharyngotonsillitis on the basis of Centor criteria, ${ }^{14}$ which includes the following: Fever $>38.5^{\circ} \mathrm{C}$, anterior cervical lymphadenopathy, absence of cough and tonsillar exudate. Children with a Centor score of 4 or 3 were grouped as "severe tonsillitis", those with a Centor score of 2 were termed "moderate tonsillitis" and those with a Centor score of 1 were called "mild Tonsillitis". The children were termed "healthy" when Centor score was 0.

A total of 310 children fulfilling the inclusion criteria were admitted indoor. The cases were divided randomly through random number tables into two groups, Group A and Group B. Children in Group A $(n=155)$ were given injection co-amoxiclav 50 units $/ \mathrm{kg} /$ day in 3 divided doses and those in Group $B \quad(n=155)$ were given injection benzyl penicillin 25000 units $/ \mathrm{kg} /$ day in 3 divided doses, intravenously.

Both these groups were compared in terms of efficacy of treatment, safety and cost effectiveness. Efficacy was assessed through improvement/ decrease (reduction in fever, decrease in tonsillar exudates and settling lymphadenopathy) in Centor Criteria score on a daily basis. Improvement/ decrease in Centor Criteria score was charted for all cases till they recovered. Children were discharged after they had recovered fully and their Centor score became zero/nil. Group A children were prescribed syrup co-amoxiclav $\quad(50 \mathrm{mg} / \mathrm{kg} /$ day divided in 3 doses) and Group B, syrup penicillin $V$ ( $25 \mathrm{mg} / \mathrm{kg} /$ day in 3 divided dosage) to complete the ten days antibiotics course.

Safety was assessed by recording the frequency of hypersensitivity reactions and serious side effects of antibiotics leading to the withdrawal of the offending injection/drug. Children in both groups were administered a test dose of the antibiotic before injecting full dose of benzyl penicillin or coamoxiclav. The procedure of test dose comprised of giving $10 \%$ of antibiotic dose slowly intravenously over 5 minutes. The child was subsequently observed for any allergic reaction (urticaria, shortness of breath, angioedema, itching, nausea, vomiting, anaphylaxis, etc.) for 30 to 60 minutes. A trained nurse supervised the test dose and full dose administration. All the cases were also observed for any serious side effects of both antibiotics. In Group A (co-amoxiclav group), children were observed for severe vomiting, diarrhea, abdominal pain and clinical jaundice. In Group B (benzyl penicillin group), children were observed for seizures and blood dyscrasias. Complete blood picture, liver and renal function tests were carried out every 48 hours to detect any serious side effect of the antibiotics being used.

Cost effectiveness was compared in terms of total cost of injections (co-amoxiclav versus benzyl penicillin), which were administered to the children of both groups.

Data was analyzed with help of SPSS (Statistical Package for Social Sciences) version 21. Frequencies were expressed by percentages. Chi square test was used to compare the qualitative variables, while independent $T$ test was used to analyze quantitative variables. $P$-value $<0.05$ was taken as statistically significant.

Clinical Trial Registration: Clinicaltrials.govNCT04215770.

\section{Results}

There were 310 cases, 155 in each group. Overall, there were 163 (52.58\%) males and 147 (47.42\%) females. The age range of patients was from 5 to 15 years with a mean age of $9.66 \pm 3.08$ years. Both 
groups $A$ and $B$ were matched in terms of age and gender (Table I).

\begin{tabular}{|c|c|c|c|}
\hline \multicolumn{4}{|c|}{$\begin{array}{l}\text { Table I: Baseline characteristics of group A and B } \\
\qquad(n=310)\end{array}$} \\
\hline Variables & Group A & Group B & $P$-value* \\
\hline $\begin{array}{l}\text { Mean Age } \\
\text { (Years) }\end{array}$ & $9.35 \pm 3.17$ & $9.96 \pm 2.96$ & 0.083 \\
\hline $\begin{array}{l}\text { Male } \\
(n=163)\end{array}$ & 80 (51.61\%) & 83 (53.55\%) & \multirow{2}{*}{0.733} \\
\hline $\begin{array}{l}\text { Female } \\
(n=147)\end{array}$ & 75 (48.39\%) & 72 (46.45\%) & \\
\hline
\end{tabular}

${ }^{*} P$-value $<0.05$ was considered statistically significant

Group A-Injection coamoxiclav; Group B-Injection benzyl penicillin

Centor score was evaluated and documented for each child on admission, then checked daily and recorded till the child recovered i.e. Centor score was nil/zero. Children were discharged from hospital when Centor score became nil/zero. Table II shows mean Centor score record of children on admission and subsequent days till recovery. Mean duration for complete resolution i.e. hospital stay was $4.13 \pm 0.375$ days in Group A, and 4.09 \pm 0.377 days in Group B ( $P=0.458)$.

The overall frequency of allergic reactions to both penicillin group antibiotics was $1.61 \%$. There were only $2(1.29 \%)$ cases of allergic reactions in Group A and 3 (1.94\%) cases in Group B, indicating that both antibiotics are safe for use in children $(P=0.652)$. There were no serious side effects to any of these two antibiotics in our study, except the allergic (hypersensitivity) reactions. Regular complete blood picture, liver and renal function tests in all cases were normal and did not show any blood dyscrasias, liver or renal compromise. Mean cost of antibiotic drug for each child in Group A was Rs. $965.9 \pm 298$ and in Group B, Rs. $152.4 \pm 52.8$. There was significant difference in cost of both these injections, benzyl penicillin being more cost effective $(P=0.000)$. Price of one intravenous injection of amoxiclav $600 \mathrm{mg}$ was Rs. $80^{15}$ and that of benzyl penicillin 5 lac units was Rs. $8,{ }^{16}$ respectively (Table III).

\begin{tabular}{|c|c|c|c|c|c|}
\hline \multicolumn{6}{|c|}{$\begin{array}{r}\text { Table II: Comparison of both Grou } \\
\text { Centor Score }\end{array}$} \\
\hline $\begin{array}{l}\text { Day Centor } \\
\text { Score } \\
\text { Recorded }\end{array}$ & Groups & $\mathrm{n}$ & $\begin{array}{l}\text { Mean } \\
\text { Centor } \\
\text { Score }\end{array}$ & SD & $\begin{array}{c}P \text { - } \\
\text { value* }\end{array}$ \\
\hline \multirow{2}{*}{$\begin{array}{l}\text { Admission } \\
\text { Day }\end{array}$} & Group A & 155 & 3.96 & 0.195 & \multirow{2}{*}{0.768} \\
\hline & Group B & 155 & 3.97 & 0.179 & \\
\hline \multirow{2}{*}{ Day 1} & Group A & 155 & 2.97 & 0.396 & \multirow{2}{*}{0.340} \\
\hline & Group B & 155 & 2.93 & 0.447 & \\
\hline \multirow{2}{*}{ Day 2} & Group A & 155 & 2.12 & 0.419 & \multirow{2}{*}{0.054} \\
\hline & Group B & 155 & 2.03 & 0.406 & \\
\hline \multirow{2}{*}{ Day 3} & Group A & 155 & 1.11 & 0.390 & \multirow{2}{*}{0.472} \\
\hline & Group B & 155 & 1.08 & 0.391 & \\
\hline \multirow{2}{*}{ Day 4} & Group A & 155 & 0.14 & 0.352 & \multirow{2}{*}{0.632} \\
\hline & Group B & 155 & 0.13 & 0.332 & \\
\hline \multirow{2}{*}{ Day 5} & Group A & 155 & 0.01 & 0.081 & \multirow{2}{*}{0.559} \\
\hline & Group B & 155 & 0.01 & 0.114 & \\
\hline
\end{tabular}

$* P$-value $<0.05$ was considered statistically significant. Group A-Children on Injection coamoxiclav; Group BChildren on Injection benzyl penicillin; SD-Standard Deviation; n-Number of children

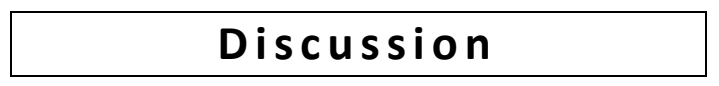

Streptococcal tonsillitis/pharyngotonsillitis is one of the most common cause of hospital visits in children. It can cause serious complications including rheumatic heart disease and acute renal failure. ${ }^{14}$ Antibiotics have to be used to eradicate Streptococcus pyogenes to prevent these complications which are serious health issues and cause of a worldwide economic burden.

Co-amoxiclav and benzyl penicillin both belong to the Penicillin group of antibiotics. They are betalactam antibiotics with bactericidal action and are effective against Streptococcus pyogenes. In literature, the allergic reactions of penicillins occur 1 in 5000 patients. ${ }^{17}$

In Pakistan, till date, no such study has been carried out to compare these two drugs for tonsillitis or pharyngotonsillitis. 


\begin{tabular}{|l|c|c|c|c|c|c|}
\hline \multicolumn{7}{|c|}{ Table III: Comparison of cost-effectiveness of group A and group B antibiotics } \\
\cline { 1 - 5 } \multicolumn{1}{|c|}{ Groups } & Antibiotics & $\mathbf{n}$ & $\begin{array}{c}\text { Mean Cost } \\
\text { (Rs.) }\end{array}$ & Standard Deviation & $\begin{array}{c}\text { Total cost } \\
\text { (Rs.) }\end{array}$ & \multirow{2}{*}{$\boldsymbol{P}$-value* } \\
\hline A & Co-amoxiclav & 155 & 965.88 & 297.99 & 147780.0 & \multirow{2}{*}{0.000} \\
\hline B & Benzyl Penicillin & 155 & 152.36 & 52.82 & 23160.0 & \\
\hline Total & & 310 & 560.46 & 460.19 & 170940.0 & \\
\hline
\end{tabular}

$* P$-value $<0.05$ was considered statistically significant

Baomah et al. compared co-amoxiclav with benzyl penicillin in the treatment of Ludwigs angina in Ghana, and found that both these drugs are equally effective. ${ }^{18}$ Agweyu et al. compared oral amoxycillin with benzyl penicillin in Kenyan children with severe pneumonia and found no difference in their efficacy. ${ }^{19}$ Atkinson et al. compared oral amoxicillin with intravenous benzyl penicillin in patients of community-acquired pneumonia, and found equal efficacy of these two pharmacologic agents. ${ }^{20}$ Similarly, we found both these drugs safe and equally effective in treating severe tonsillitis or pharyngotonsillitis in children. However, there was significant difference in cost-effectiveness of both these drugs: Benzyl penicillin being very cheap as compared to co-amoxiclav. As already mentioned, one Injection of co-amoxiclav $600 \mathrm{mg}$ costs Rs. 80.00 versus Rs 08.00 of benzyl penicillin. ${ }^{15,16}$ Thus, there is significant difference of prices between the two drugs with similar efficacy and safety profile. ${ }^{18}$

\section{Conclusion}

Intravenous co-amoxiclav and benzyl penicillin have similar efficacy and safety profile in the treatment of severe streptococcal tonsillitis. However, benzyl penicillin is more cost effective than co-amoxiclav in our study population.

\section{References}

1. Abraham ZS, Bazilio J, Kahinga AA, Manyahi J, Ntunaguzi D, Massawe ER. Prevalence and bacteriology of tonsillitis in patients attending otorhinolaryngology department at Muhimbili
National Hospital, Dar es Salaam Tanzania. Tanzan Med J. 2019; 46(1): 33-40.

2. Alasmari NSH, Bamashmous ROM, Alshuwaykan RMA, Alahmari MAM, Almubarak RM, Mohammed AA, et al. Causes and treatment of tonsillitis. Egypt J Hosp Med. 2017; 69(8): 2975-80. Doi: 10.12816/ 0042838

3. Okoye EL, Obiweluozor CJ, Uba BO, Odunukwe FN. Epidemiological survey of tonsillitis caused by Streptococcus Pyogenes among children in Awka Metropolis (A case study of hospitals in Awka Community, Anambra State). IOSR J Pharm Biol Sci. 2016; 11(3): 54-58. Doi: 10.2139/ssrn.3448992

4. Eisenberg MJ. Rheumatic heart disease in the developing world: prevalence, prevention, and control. Eur Heart J. 1993; 14(1): 122-8. Doi: 10.1093/eurheartj/14.1.122

5. Brook I. Foot PA. Isolation of Methicillin Resistant Staphylococcus Aureus from the surface and core of tonsils in children. Int J Pediatr Otorhinolaryngol. 2006; 70(12): 2099-2102. Doi: 10.1016/j.ijporl. 2006.08.004

6. Najam Y, Walla FL, Iqbal A. The efficacy and safety of cefaclor in respiratory infections amongst Pakistani children. J Pak Med Assoc. 2000; 50(9): 289-93. PMID: 11043017

7. Siddiqui SJ, Awan A, Ekangakic A, Stocks JM, Sheikh JA, Ahmad TM, et al. An evaluation of cefaclor in Pakistani children with pharyngotonsillitis. J Pak Med Assoc. 2002; 52(10): 451-6. PMID: 12553673

8. Van Kempen MJ, Rijkers GT, Van Cauwenberge PB. The immune response in adenoids and tonsils. Int Arch Allergy Immunol. 2000; 122(1): 8-19. Doi: 10.1159/000024354

9. Farooqi IA, Akram T, Zaka M. Incidence and empiric use of antibiotic therapy for tonsillitis in children. Int J Appl Res. 2017; 3(12): 323-27. 
10. Huovinen P. Causes, diagnosis and treatment of pharyngitis. Comp Ther. 1999; 25(6-7): 326-9. Doi: 10.1007/BF02944278

11. Pichichero ME. Group A streptococcal tonsillopharyngitis: cost effective diagnosis and treatment. Ann Emerg Med. 1995; 25(3): 390-403. Doi: 10.1016/s0196-0644(95)70300-4

12. Shulman ST, Bisno AL, Clegg HW, Gerber MA, Kaplan $E L$, Lee $G$, et al. Clinical practice guidelines for the diagnosis and management of group $A$ streptococcal pharyngitis: 2012 update by the Infectious Disease Society of America. Clin Infect Dis. 2012; 55(10): 1279-82. Doi: 10.1093/cid/cis629

13. Rathi SK, Ahmed R. Pakistan prevalence survey in acute pharyngitis. J Pak Med Assoc. 2014; 64(8): 928-31. PMID: 25252520

14. Orra M, Naos M, Ghanem S, Mehri BA, Rajab M. The diagnostic value of 'Centor Criteria' in children with group A beta hemolytic streptococcus tonsillopharyngitis. Enr J Biomed Pharm Sci. 2018; 5(8): 43-9.

15. https://dawaai.pk/benzyl-penicillin-500000-unit9231.html.

16. Co-amoxiclavin; PharmaGuide. 21st Ed. Page 610.Available online @. www.epharmaguide.com/ online.
17. Canzani D, Aldeek F. Penicillin G's function, metabolites, allergy and resistance. J Nutr Hum Health. 2017; 1(1): 28-40. Doi:10.35841/nutritionhuman-health.1.1.28-40

18. Baomah MO, Saheeb BD, Parkins GE, Nuamah I, Ndanu TA, Blankson PW. A comparative study of the efficacy of intravenous benzylpenicillin versus intravenous augmentin in the empirical management of Ludwig's angina. Ann Afr Med. 2019; 18(2): 65-9. Doi: 10.4103/aam.aam_22_18

19. Agweyu A, Gathara D, Oliwa J, Muniga N, Edwards T, Allen $E$ et al. Oral Amoxicillin versus benzyl penicillin for severe pneumonia among Kenyan children: A pragmatic randomized controlled noninferiority trial. Clin Infect Dis. 2015; 60(8): 1216-24. Doi: 10.1093/cid/ciu1166

20. Atkinson $M$, Lakhanpaul $M$, Smyth $A$, Vyas $H$, Weston V, Sithole J. Comparison of oral amoxicillin and intravenous benzyl penicillin for community acquired pneumonia (pivot trial): A multicenter pragmatic randomized controlled equivalence trial. Thorax. 2007; 62(12): 1102-06. Doi: 10.1136/thx. 2006.074906 